\title{
Research on Thermal Stiffness of Machine Tool Spindle Bearing under Different Initial Preload and Speed Based on FBG Sensors
}

\section{Yanfang DONG ( $\nabla$ xiaoqidong104@163.com )}

Henan University of Science and Technology https://orcid.org/0000-0001-9834-7157

\section{Feifan CHEN}

Henan University of Science and Technology

\section{Tuanliang LU}

Henan University of Science and Technology

\section{Ming QIU}

Henan University of Science and Technology

\section{Research Article}

Keywords: Machine tool spindle bearing, temperature rise, thermal stiffness, Fiber Bragg grating (FBG)

Posted Date: July 7th, 2021

DOI: https://doi.org/10.21203/rs.3.rs-669655/v1

License: (c) (i) This work is licensed under a Creative Commons Attribution 4.0 International License. Read Full License

Version of Record: A version of this preprint was published at The International Journal of Advanced Manufacturing Technology on November 12th, 2021. See the published version at https://doi.org/10.1007/s00170-021-08330-6. 


\title{
Research on thermal stiffness of machine tool spindle bearing under different initial preload and speed based on \\ FBG sensors
}

\author{
DONG Yanfang ${ }^{1,2,3}$, CHEN Feifan ${ }^{1,2}$, LU Tuanliang ${ }^{1,2}$, QIU Ming ${ }^{1,2^{*}}$ \\ ${ }^{1}$ School of Mechatronics Engineering, Henan University of Science and Technology, \\ Luoyang, 471003, China \\ ${ }^{2}$ Henan Provincial Cooperative Innovation Center for Advanced Manufacturing of \\ Mechanical Equipment, Luoyang, 471003, China \\ ${ }^{3}$ Hangzhou Bearing Test \& Research Center Co. Ltd., Hangzhou, 310000, China \\ *Corresponding author e-mail: qiuming69@126.com
}

\begin{abstract}
As a key parameter, stiffness determines the dynamic characteristics of the bearing and the spindle unit. However, the interaction of the spindle speed, initial preload, and cutting force will change the bearing stiffness characteristics during the running process cause the thermal expansion of spindle unit components. Aiming at real-time online monitoring of the thermal characteristics of machine tool spindle bearing stiffness, this paper proposed a fiber Bragg grating (FBG) sensors network. And under different axial loads, combined axial and specific radial load, the bearing temperature rise, thermally induced preload, and thermal stiffness are studied. The results show that the thermal stiffness of the bearing decreases with the increase of the spindle speed, and there is an optimal initial preload at the speed to maximize the thermal stiffness of the bearing, and the thermally induced preload has an additional pre-tightening effect on the bearing.
\end{abstract}

Keywords: Machine tool spindle bearing, temperature rise, thermal stiffness, Fiber Bragg grating (FBG)

\section{Introduction}

As the core component of the spindle unit, angular contact bearing is widely used in high speed spindle unit cause enduring high speed, axial and radial force simultaneously. Hence high speed, axial and radial cause the bearing to produce a great deal of heat. The actual running and the non-working state of the bearing state has a significant difference, especially the bearing stiffness which is the key parameter for evaluating bearing running status. Moreover, excessive heat generation in the spindle bearing will induce uneven thermal expansion in different spindle elements leading to bearing rings uneven thermal deformation. Therefore, there is a urgent need to 
investigate the thermal stiffness of bearings to evaluate the bearing running status and ensure the reliable operation of high speed spindle units.

Bearing stiffness refers to the ability of a structure to resist elastic deformation when subjected to force. In actual working conditions, the elastic deformation and thermal expansion of the machine tool spindle bearing will affect each other, and many scholars put forward the concept of bearing thermal stiffness, that is, the magnitude of the load and temperature causes the parts thermoelastic coupling deformation. Consequently, exploring the bearing thermal stiffness characteristics should consider the spindle speed, cutting loads and initial preload which is necessary for angular contact bearing. Jin et al.[1] established a heat generation model of ball bearing based on internal load distribution. Zhao et al.[2] studied the load characteristics and friction coefficient of angular contact ball bearing at high speed. Liu Mingyao et al.[3] improved that Cutting force changes the distribution of the temperature field of the spindle bearing, especially after the loading of radial cutting force, the temperature rise of bearing zone of the ball bearing is higher than the non-bearing area. ZHANG Yanfei et al.[4] estimated heat generation fluctuations in bearing local contact zone and proved the bearing has an uneven heat generation in the working process. Wu Wenwu et al.[5, 6] studied the influences of non-uniform load on bearing thermal performance under different preloads and established the stiffness function for calculating the local contact deformation of angular contact ball bearings with uneven preload through analysis to predict the stiffness of the bearing. Huang Weidi et al.[7] established a comparative model for calculating bearing stiffness for different preload mechanisms by analyzing the preloading process, and discussed the effects of spindle speed and radial force on the dynamic characteristics and stiffness of the bearing under different preload mechanisms.

The bearing thermal characteristics are effected by the external factors significantly. However, the tests are very limited. Traditional measurement methods are very difficult to monitor the bearing statues directly. LI Jiandong et al. [8,9] developed an improved thermo-mechanical model for studying the effects of the various factors on the transient preload, and verified by the dedicated test rig which is interfering with the spindle unit operation. There is a serious lack of test methods embedded in the spindle unit to ensure the real-time monitoring of the bearing statues.

At present, the detection methods of temperature field and thermal stress state of spindle bearings are very limited. And it is harder to realize online monitoring of bearing thermal stiffness characteristics to reflect the true service information of the 
bearing. In order to solve this problem, this paper uses the measurement advantages of FBG "one line and multiple points"[10], builds a real-time online monitoring system for the service status of the FBG embedded spindle bearing to complete the thermal characteristic test of the spindle unit, and explores the change law of spindle bearing thermal stiffness under the action of spindle speed, initial preload and cutting force.

\section{Real-time online monitoring system for spindle bearing service status}

\subsection{FBG Measurement Principle}

This paper uses FBG sensing technology to build an embedded real-time online network for monitoring the service status of spindle bearings to complete the measurement of the bearing temperature and strain field.

FBG sensor can reflect specific wavelengths of light signal, and the first-order Bragg wavelength can be expressed as ${ }^{[13]}$ :

$$
\lambda_{B}=2 \cdot n_{0} \cdot l
$$

where, $n_{0}$ is the effective refractive index of the grating, $l$ is the grating interval.

It can be seen from formula (1) that the reflected wavelength of the FBG depends on the grating interval and effective refractive index. Changes in the temperature or strain of the external environment will cause the grating pitch of the grating itself to change, resulting in a change in the wavelength of the reflected wave. The demodulation device derives the external temperature or strain by detecting the change of wavelength. When the external temperature, stress, etc. are measured, the change in the center wavelength of the FBG can be expressed as:

$$
\Delta \lambda_{B}=K_{T} \cdot \Delta T \cdot \lambda_{B}
$$

where, $\Delta T$ is the temperature difference before and after the test, ${ }^{\circ} \mathrm{C}, K_{T}$ is the temperature sensitivity coefficient of the optical fiber.

$$
K_{T}=\alpha_{f}+\zeta
$$

where, $\alpha_{f}$ is the thermal expansion coefficient of the optical fiber material, $\zeta$ is the therm-optical coefficient of the optical fiber material.

Due to the thermal expansion effect of the matrix material, when its expansion is completely transferred to the fiber grating, the reflection wavelength change can be expressed as:

$$
\Delta \lambda_{B}=\left(1-P_{e}\right) \cdot \Delta \varepsilon \cdot \lambda_{B}
$$

where, $P_{e}$ is the elastic-optical coefficient of the optical fiber, $\Delta \varepsilon$ is the structural strain 
of the optical fiber.

\subsection{FBG Embedded Bearing Service Status Real-time Online Monitoring network}

The real-time online monitoring network of the spindle bearing service status built in this paper is a distributed measurement system based on FBG sensors which are connected in one fiber. Fig. 1 shows the layout of the spindle front bearings service statuses testing system. Through the demodulator and PC, the wavelength changes of the FBG sensors under the action of axial preload and temperature rise are measured in real-time.

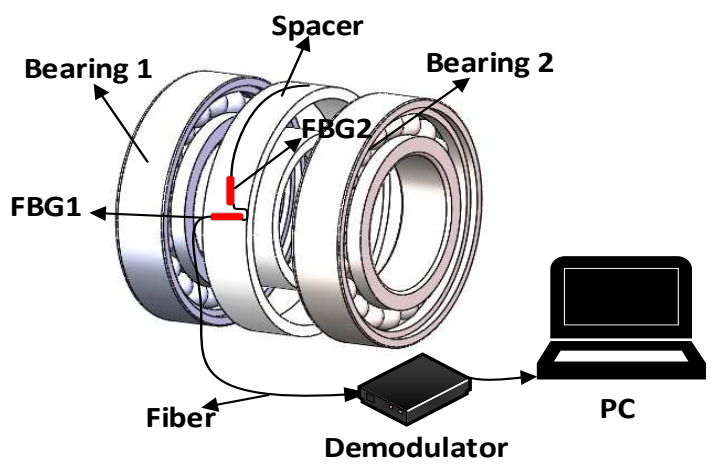

Fig. 1 The monitoring system of spindle front bearings

The designed new structure spacer in this paper which is installed between the front and rear tandem bearings is shown in Fig. 2. The improved bearing outer spacer is composed of two rings and four constant cross-section cantilever beams. Eight FBG sensors are pasted on the constant cross-section cantilever beam, and each beam has two FBG sensors. The cantilever beam measures the axial strain change $\Delta \varepsilon$ caused by the thermal expansion of the spindle unit components, so the measured axial force of a single cantilever beam is $E A \cdot \Delta \varepsilon l$, and then the axial force borne by the entire spacer is $E A \cdot(\Delta \varepsilon 1+\Delta \varepsilon 2+\Delta \varepsilon 3+\Delta \varepsilon 4)$, which is the bearing preload force of axial load, where $E$ is the elastic modulus of the spacer ring material, $A$ is the cross-sectional area of the cantilever beam with constant cross-section.

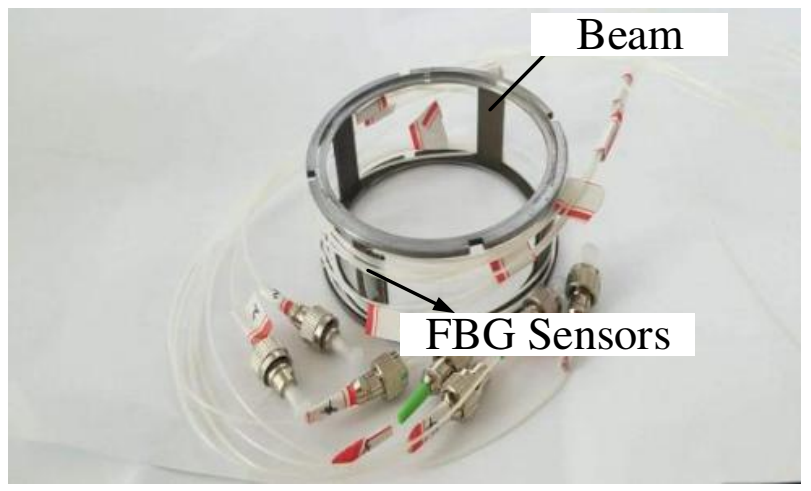

Fig. 2 FBG sensors based spacer

Since the FBG is sensitive to temperature and strain at the same time, when 
measuring the initial preload and the axial strain caused by the thermal expansion of the spindle unit assembly, it is necessary to exclude the influence of environmental temperature changes. This paper uses the FBG paste method shown in Fig. 1 to compensate the effects of environmental temperature changes. Since the cantilever beam is compressed in the axial direction, the corresponding strain will also be generated in the vertical axial direction. These strains include the influence of the Poisson's ratio of the cantilever beam structure and the influence of the ambient temperature. Using this rule, the fiber grating FBG1 is pasted on the cantilever beam along the axial direction to directly monitor the structural strain caused by the axial force $\mathrm{Fa}_{1}$ generated by the initial preload and the thermal expansion of the components. The FBG2 is pasted perpendicular to FBG1. The distance between the two FBG is relatively close, so it can be considered that they have the same ambient temperature. Since FBG2 in the vertical direction is not affected by changes in axial force Fa1, it only senses the effects of isotropic strain and ambient temperature caused by the Poisson's ratio of the structure, so the signals collected by FBG2 can be used to compensate for the effects of FBG1 due to changes in ambient temperature influences.

The axially pasted fiber grating FBG1 senses strain generated by the initial preload and the axial force $\mathrm{Fa}$ of the components thermal expansion, and the change of the ambient temperature, so the center wavelength change $\Delta \lambda_{B l}$ of FBG1, can be expressed as:

$$
\Delta \lambda_{B 1}=\left[-\left(1-P_{e}\right) \cdot \frac{F_{a}}{E w h}+\left(\alpha_{f}+\xi\right) \cdot \Delta T\right] \cdot \lambda_{B 1}
$$

The FBG2 is pasted in the vertical direction, and the cantilever beam is compressed in the axial direction and strain is also generated in the vertical axial direction. In addition to the environmental temperature change, the FBG2 center wavelength change $\Delta \lambda_{B 2}$ can be expressed as:

$$
\Delta \lambda_{B 2}=\left[v \cdot\left(1-P_{e}\right) \cdot \frac{F_{a}}{E w h}+\left(\alpha_{f}+\xi\right) \cdot \Delta T\right] \cdot \lambda_{B 2}
$$

where, $\lambda_{B 1}$ and $\lambda_{B 2}$ are the initial center wavelengths of FBG1 and FBG2, respectively, $E$ is the elastic modulus of the spacer material, $v$ is the Poisson's ratio of the spacer material, $w$ is the width of the beam, $h$ is the thickness of the beam.

The combination of (5) and (6) can eliminate the influence of the ambient temperature $\Delta T$ on the central wavelength of FBG sensors, the influence of the ambient temperature on FBG1 can be compensated by the collected data of FBG2.

Since the FBG sensor is pasted close to the tested bearing, it is approximately 
considered that the measured temperature rise is the bearing temperature rise, so the spindle bearing temperature rise is:

$$
\Delta T=\frac{\Delta \lambda_{B 2} \cdot \lambda_{B 1}-v \Delta \lambda_{B 1} \cdot \lambda_{B 2}}{\lambda_{B 1} \cdot \lambda_{B 2}(1-v)\left(\alpha_{f}+\xi\right)}
$$

Given the structural characteristics of the spindle unit in this paper, the thermal displacement of single bearing can be expressed as:

$$
2 \Delta \varepsilon_{\mathrm{b}}=\Delta \varepsilon 1+2 \Delta B+\Delta l
$$

where, $\Delta \varepsilon 1$ is the deformation of the spacer ring measured by the fiber grating, $\Delta B$ is the axial linear expansion of the bearing, $\Delta l$ is the axial linear expansion of the spacer, respectively by formulas (9) (11) calculated.

$$
\begin{gathered}
\Delta \varepsilon 1=\frac{F_{a 1}}{E w h}=\frac{\Delta \lambda_{B 2} \cdot \lambda_{B 1}-\Delta \lambda_{B 1} \cdot \lambda_{B 2}}{\lambda_{B 1} \cdot \lambda_{B 2}(1-v)\left(1-P_{\mathrm{e}}\right)} \\
\Delta B=\alpha_{\mathrm{b}} \cdot B \cdot \Delta T \\
\Delta l=\alpha_{l} \cdot l \cdot \Delta T
\end{gathered}
$$

where, $\alpha_{b}$ and $\alpha_{l}$ are the linear expansion coefficients of the bearing and spacer materials, $l$ is the length of the beam, $B$ is the width of bearing.

The comparison shows that $\Delta \varepsilon l>>\Delta B+\Delta l$, so the thermal displacement of the spindle bearing can be approximated as:

$$
\Delta \varepsilon_{b}=\frac{1}{2} \Delta \varepsilon 1=\frac{F_{a 1}}{2 E w h}=\frac{\Delta \lambda_{B 2} \cdot \lambda_{B 1}-\Delta \lambda_{B 1} \cdot \lambda_{B 2}}{2 \lambda_{B 1} \cdot \lambda_{B 2}(1-v)\left(1-P_{\mathrm{e}}\right)}
$$

The thermally induced preload $F a_{1}$ of one cantilever beam during the thermal expansion of the main spindle unit assembly is:

$$
F_{a 1}=\frac{\left(\Delta \lambda_{B 2} \cdot \lambda_{B 1}-\Delta \lambda_{B 1} \cdot \lambda_{B 2}\right) E w h}{\lambda_{B 1} \cdot \lambda_{B 2}(1-v)\left(1-P_{\mathrm{e}}\right)}
$$

In the same way, the other three temperature rise data $\left(\Delta T_{2}, \Delta T_{3}, \Delta T_{4}\right)$, strain change data $\left(\Delta \varepsilon_{2}, \Delta \varepsilon_{3}, \Delta \varepsilon_{4}\right)$, and thermally induced preload data $\left(F a_{2}, F a_{3}, F a_{4}\right)$ can be obtained, through this environmental temperature compensation method, the service status of the spindle bearing can be accurately monitored through the FBG network, and the bearing service status information such as the temperature field of the spindle bearing and the thermally induced preload can be collected online in real-time, and the thermal stiffness of the bearing can be achieved.

\subsection{FBG Sensors Calibration}

Taking into account the influence of the sensor substrate and pasting effect on the sensitivity of FBG sensors, the FBG sensors on one beam are calibrated by applying 
axial force by the hydraulic station when the spindle is stationary. The test was carried out in three groups, and the test results are shown in Fig. 3. It can be seen from Fig. that there is a good linear relationship between the pasted FBG sensors and the axial force change. When the axial force is $300 \mathrm{~N}$, the maximum test deviation is $12.4 \mathrm{~N}$, and the relative error is $4.13 \%$.

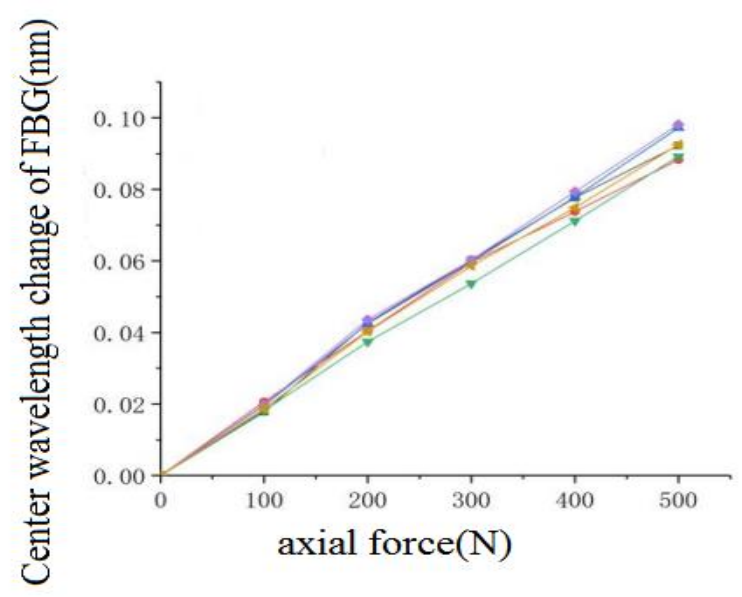

Fig. 3 Calibration results of FBG sensors

\section{Experimental research on the thermal stiffness of spindle bearings}

\subsection{Introduction to the testing platform structure}

In this paper, the TS30-70 high-speed machine tool spindle bearing test platform is used to carry out the thermal stiffness characteristics test of the spindle bearing. The test platform can realize the maximum speed 36000rpm, the application of $0-1500 \mathrm{~N}$ axial load and $0-500 \mathrm{~N}$ radial load. The composition of the test platform is shown in Fig. 4. The front and rear end of the spindle has two tandem bearings, and the bearings are arranged as ' $\mathrm{O}$ ' on the whole. When the initial preload $F a$ is applied, the front end bearings of the spindle are preloaded, and the spindle moves backward to preload the rear end bearings.

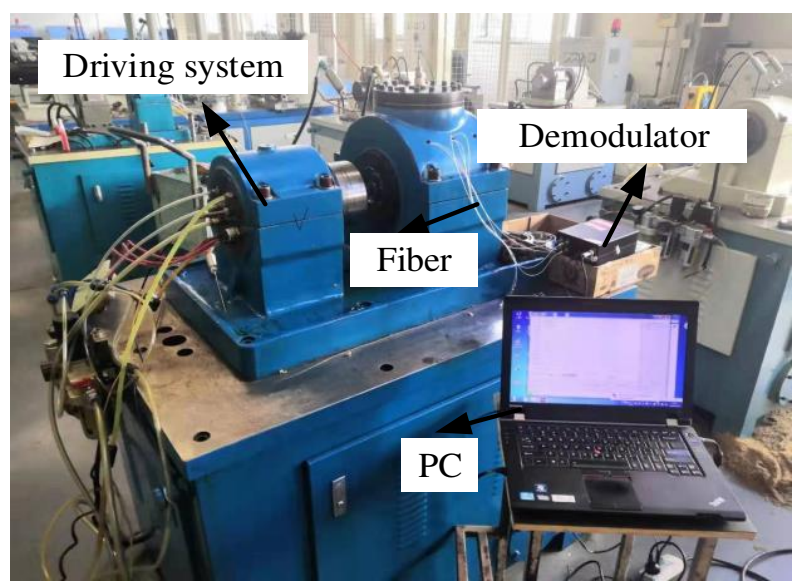

Fig. 4 TS30-70 high-speed machine tool spindle bearing test platform 
With the help of the high-speed machine tool spindle bearing test platform and the built-up real-time online monitoring system of the spindle bearing service statuses, the thermal characteristics test of the spindle bearing under only the axial load and the combined axial and radial load has been completed. Each test lasts for 3 hours and performs the next set of tests when the test machine cools to room temperature.

\subsection{Uniform thermal stiffness of spindle bearing under axial load}

During the operation of the machine tool spindle, as the spindle speed and axial force change, the spindle bearing temperature field, thermally induced preload and thermal stiffness will change. In this paper, the thermal characteristic test of the bearing with the spindle speed of 2000rpm-12000rpm and the initial preload of $350-550 \mathrm{~N}$ has been completed.

It can be seen from Fig. 5 that initial preload $350 \mathrm{~N}, 400 \mathrm{~N}$, the bearing temperature rise changes with the spindle speed in a similar way. As the spindle speed increases, the bearing temperature rise increases. It can be noticed that when the speed exceeds 10000 $\mathrm{rpm}$, the bearing temperature rises rapidly and reaches the maximum value in the early stage of the test, and then slowly decreases until it finally stabilizes. This is because the rate of heat generation is much higher than the rate of heat lost, resulting in the accumulation of heat inside the bearing. And as the temperature of the bearing increases, the viscosity of the lubricant decreases, resulting in the decrease of the viscous friction torque and heat generation rate of the bearing. However, the heat conduction is increased due to the temperature increase, so the temperature rise of the bearing decreases slowly after reaching the maximum value.

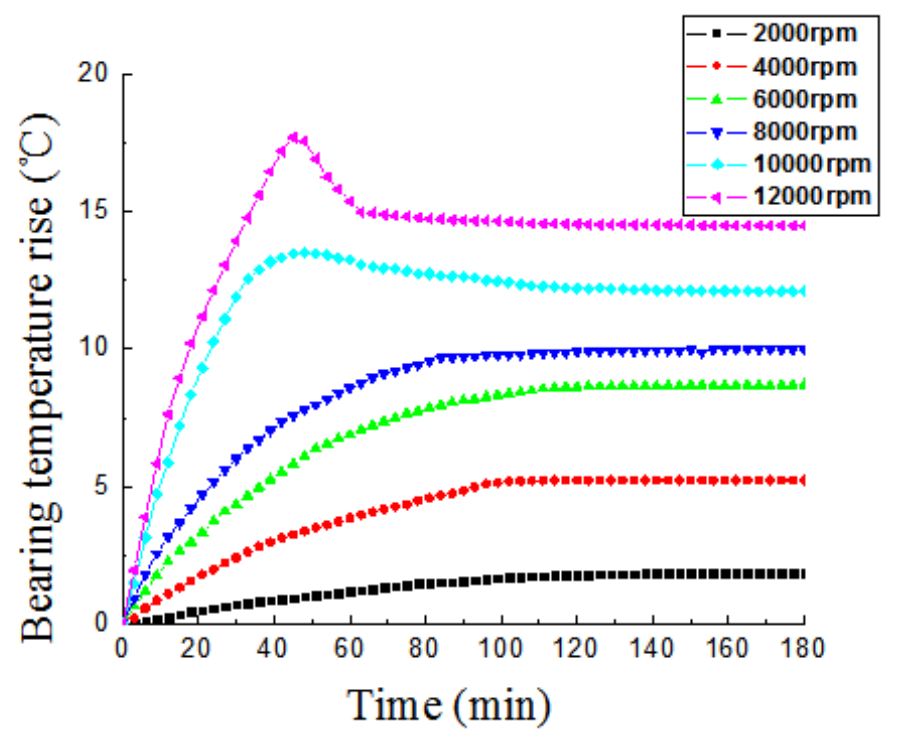

(a) Initial preload $350 \mathrm{~N}$ 


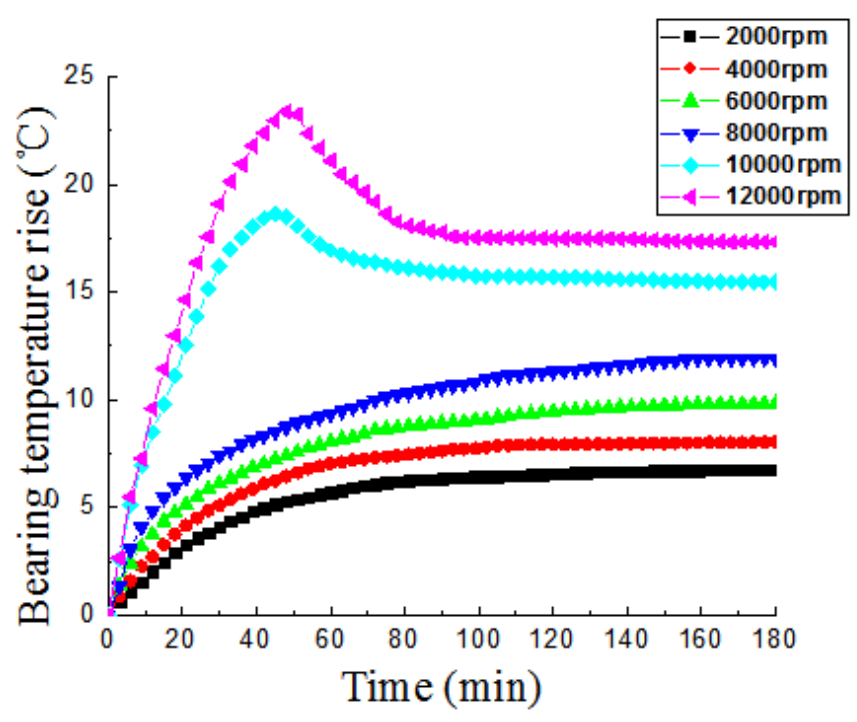

(b) Initial preload $550 \mathrm{~N}$

Fig. 5 The influence of spindle speed/initial preload on bearing temperature rise

Fig. 6 shows the results of the steady-state temperature rise of the bearing under different spindle speeds/initial preload. It can be seen that under the same initial preload, the steady-state temperature rise of the bearing increases with the increase of the spindle speed. In particular, at a certain speed, the steady-state temperature rise of the bearing has an inflection point, and the higher the speed, the lower the inflection point. This shows that for any speed, there is an optimal preload to minimize the temperature rise of the bearing. As speed rises, the optimal initial preload of the bearing also increases accordingly.

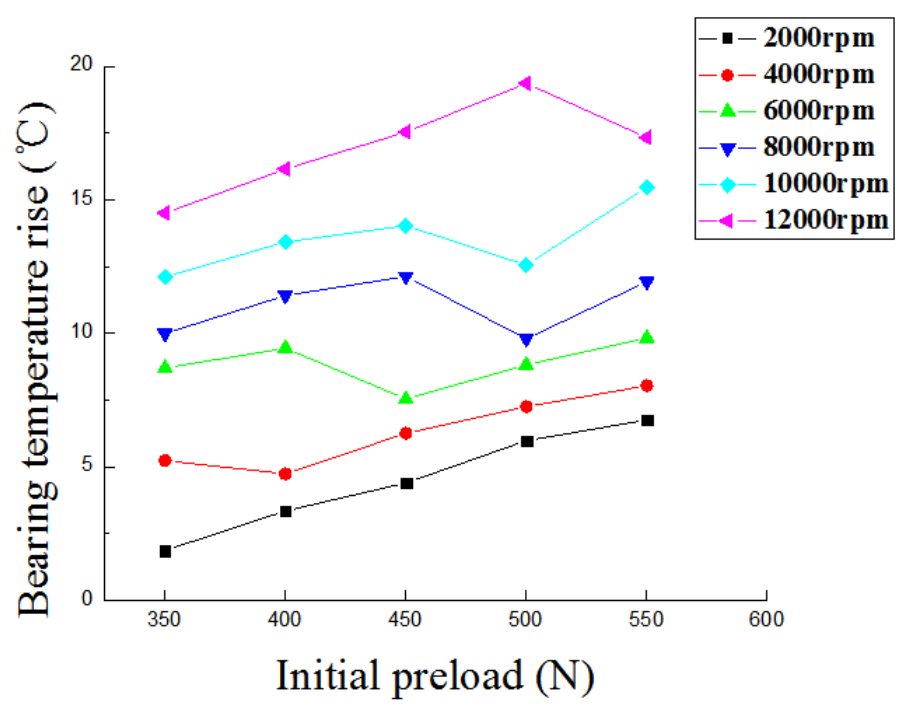

Fig. 6 Steady-state bearing temperature rise under different spindle speed/initial preload

Thermally-induced preload caused by the thermal expansion of the spindle unit components is one of the main parameters that affect the dynamic performance of the 
spindle bearing. Fig. 7 shows the change rule of bearing thermally induced preload with time under different spindle speeds/initial preload. It can be seen that under the same initial preload, the thermally induced preload of the bearing increases with the increase of the spindle speed, especially at the beginning of the test, the higher the spindle speed, the greater the increase of the thermally induced preload. After the rotation speed reaches $10000 \mathrm{rpm}$, the thermally induced preload rapidly increases to the maximum value firstly, then slowly decreases, and finally tends to a stable value. This is because the expansion rate of the rolling elements and the inner ring is higher than the expansion rate of the outer ring and the bearing housing. The bearing clearance will reduce at the beginning of the test. With the progress of heat transfer, the temperature of the rolling elements and the inner ring tend to be stable. The thermally-induced preload of the bearing tends to stabilize at the thermal equilibrium state of the whole spindle unit.

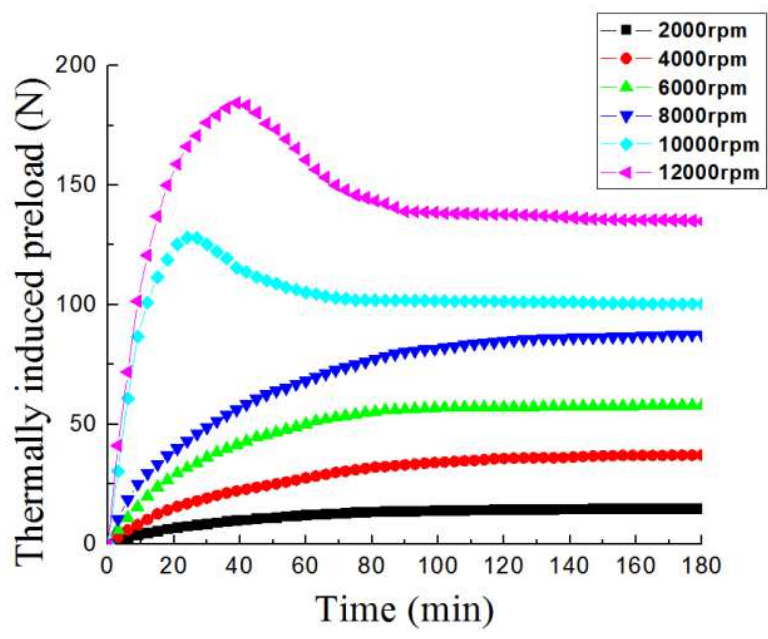

(a) Initial preload $350 \mathrm{~N}$

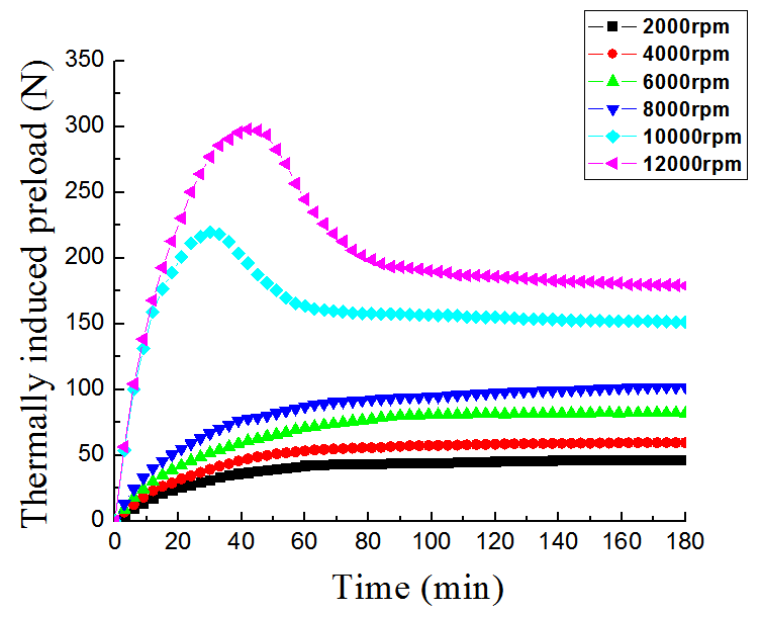

(b) Initial preload $550 \mathrm{~N}$

Fig. 7 The influence of spindle speed/initial preload on the bearing thermally induced preload

Fig. 8 shows the change curve of the steady-state thermally induced preload of the 
bearing with the initial preload at different spindle speeds. It can be seen that under the same initial preload, as the spindle speed increases, the thermally induced preload gradually increases. At higher speeds, the thermally induced preload reaches a larger value. This is because high speed will cause the spindle unit to generate more heat, resulting in greater thermal expansion of the spindle unit assembly, resulting in a higher thermally induced preload. Similar to the steady-state temperature rise of the bearing, at the same speed, there is an inflection point in the curve of the thermally induced preload with the initial preload. It also can be seen that the thermally induced preload is equivalent to the initial preload and can not be ignored.

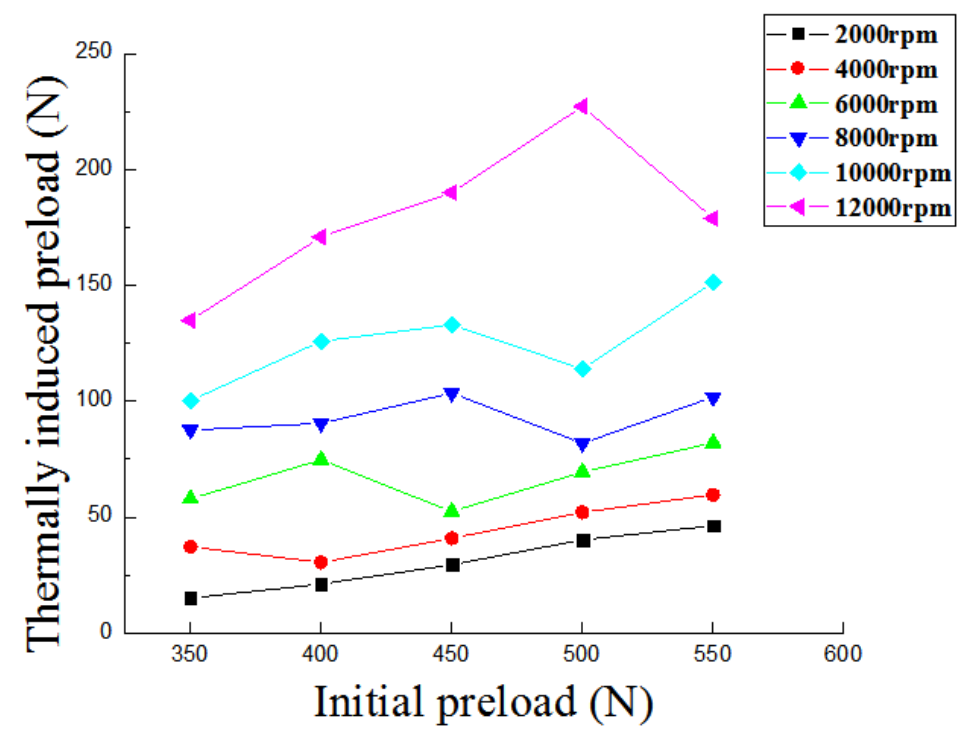

Fig. 8 Steady-state thermally induced preload of bearings with different speeds/preload

Bearing stiffness is a key parameter that determines the dynamic characteristics of the spindle unit. The initial preload of the bearing is usually used to obtain the high stiffness of the machine tool spindle. At the same time, as the speed and working conditions change, due to the positive feedback of the preload thermal closed-loop, the generation of bearing friction heat will further change the thermal stiffness characteristics of the bearing and produce thermal instability. Fig. 9 shows the influence of spindle speed/initial preload on bearing stiffness. It can be found that under a given spindle speed condition, there is an optimal initial preload to maximize the stiffness of the bearing. Too high or too low initial preload will significantly reduce the stiffness of the bearing.

Comparing Fig. 9(a) and Fig. 9(b), it can be seen that under the same working conditions, whether the thermally induced preload is considered to affect the bearing stiffness, the maximum difference is $0.32 \times 107 \mathrm{~N} / \mathrm{m}$ (the spindle speed is $8000 \mathrm{rpm}$ and 
the initial preload is $350 \mathrm{~N}$, the bearing stiffness is $1.25 \times 107 \mathrm{~N} / \mathrm{m}$ when the thermally induced preload is not considered, and the bearing stiffness is $1.57 \times 107 \mathrm{~N} / \mathrm{m}$ when the thermally induced preload is considered), this is because the thermally induced preload increases the stiffness of the bearing. Therefore, the effect of thermally induced preload on the operating state of the spindle unit should be fully considered when applying and optimizing the initial preload.

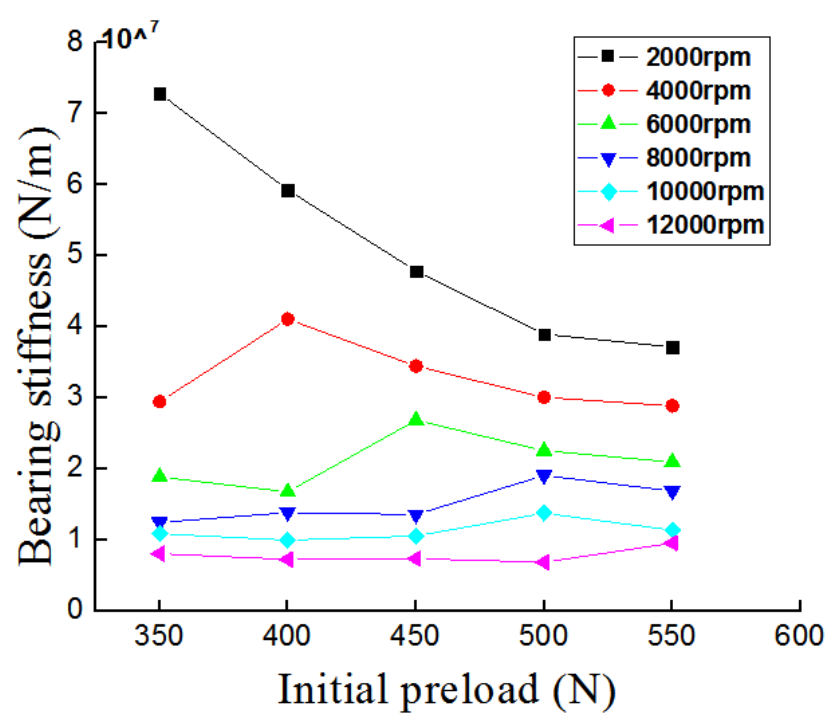

(a) Does not consider the influence of thermally induced preload

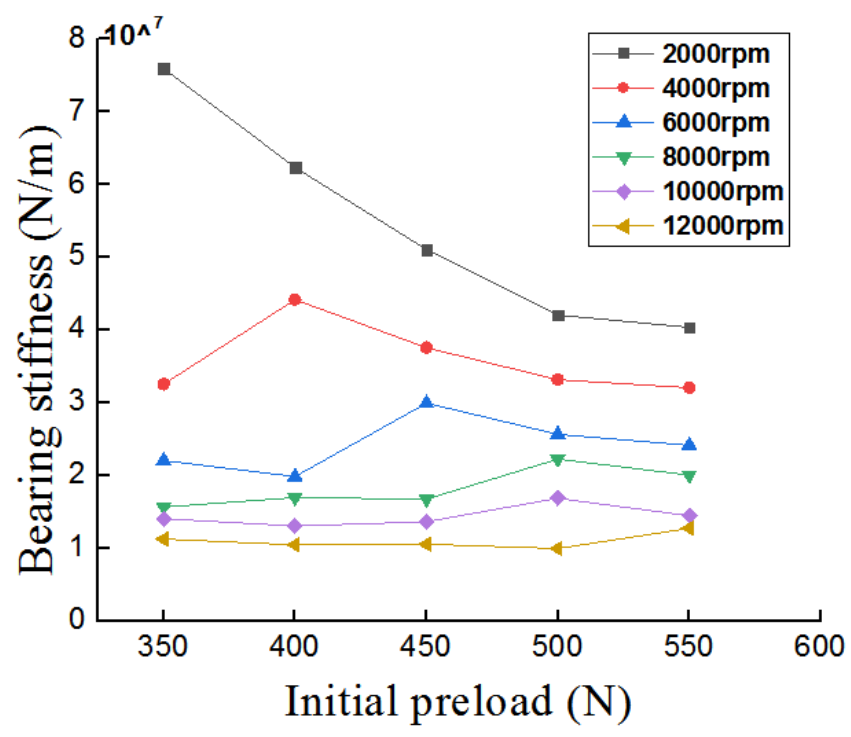

(b) Consider the influence of thermally induced preload

Fig. 9 Bearing thermal stiffness at different spindle speeds

\subsection{Non-uniform thermal stiffness of spindle bearing under combined axial and radial} load

The test condition is selected as initial preload $550 \mathrm{~N}$, the radial load is $100 \mathrm{~N}$, spindle speed is $12000 \mathrm{rpm}$ to make the degree of heterogeneity significant, and the non- 
uniform thermal characteristics of the spindle bearing are monitored through four measuring points A, B, C, and D. The position of the measuring points is shown in Fig. 10.

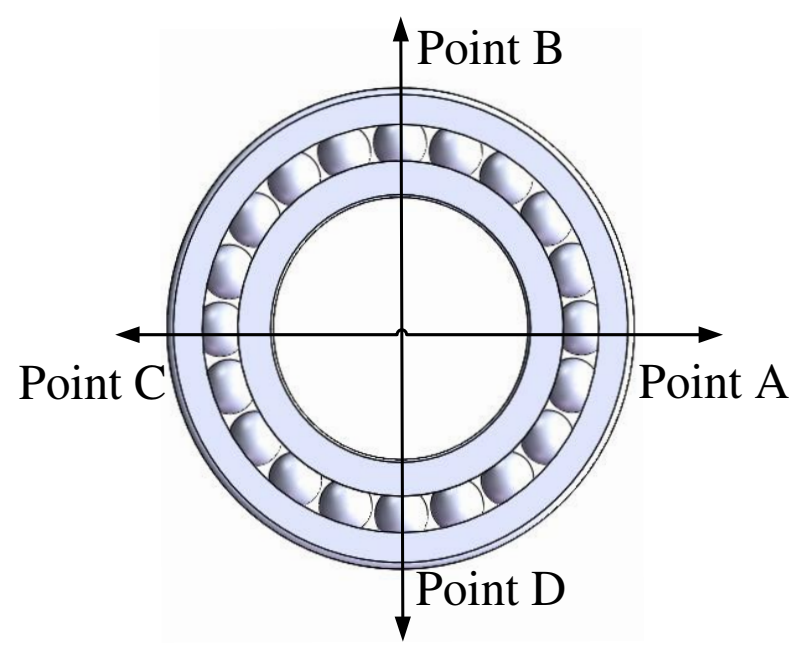

Fig. 10 Distribution of measuring points on the circumference of the bearing end surface

The entire measurement process lasted 3 hours. It can be seen from Fig. 11 that with the running time of the spindle unit, the bearing temperature first rises sharply, then drops, and finally stabilizes. After reaching the thermal equilibrium, the temperature of the measuring points $\mathrm{A}, \mathrm{B}, \mathrm{C}$, and $\mathrm{D}$ are $14.92^{\circ} \mathrm{C}, 17.84^{\circ} \mathrm{C}, 15.02^{\circ} \mathrm{C}$, $13.25^{\circ} \mathrm{C}$.

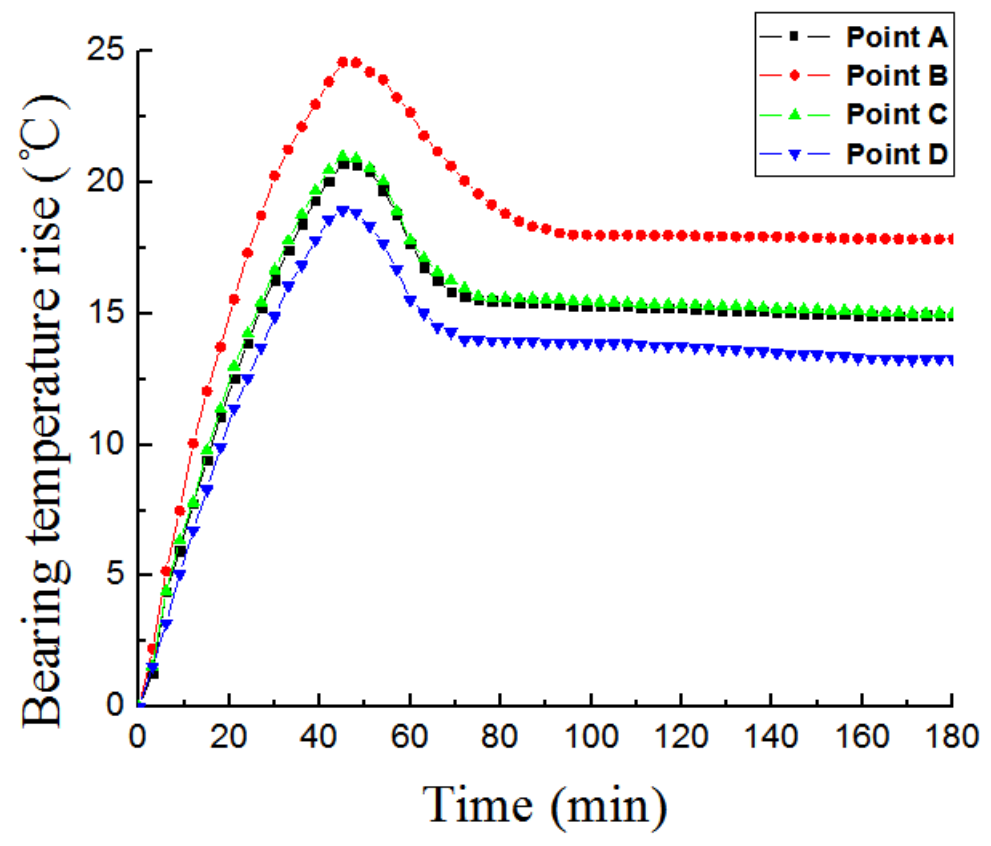

Fig. 11 Bearing temperature rise at different measuring points

Due to the significant difference in the temperature field distribution in the 
circumferential direction of the bearing under the action of the radial load, this also leads to uneven thermal expansion of the bearing rolling elements, inner and outer rings, and the bearing seat. As shown in Fig. 12, the curve of measuring point B is steeper than other measuring points while it is rising, which is also directly related to the effect of radial load.

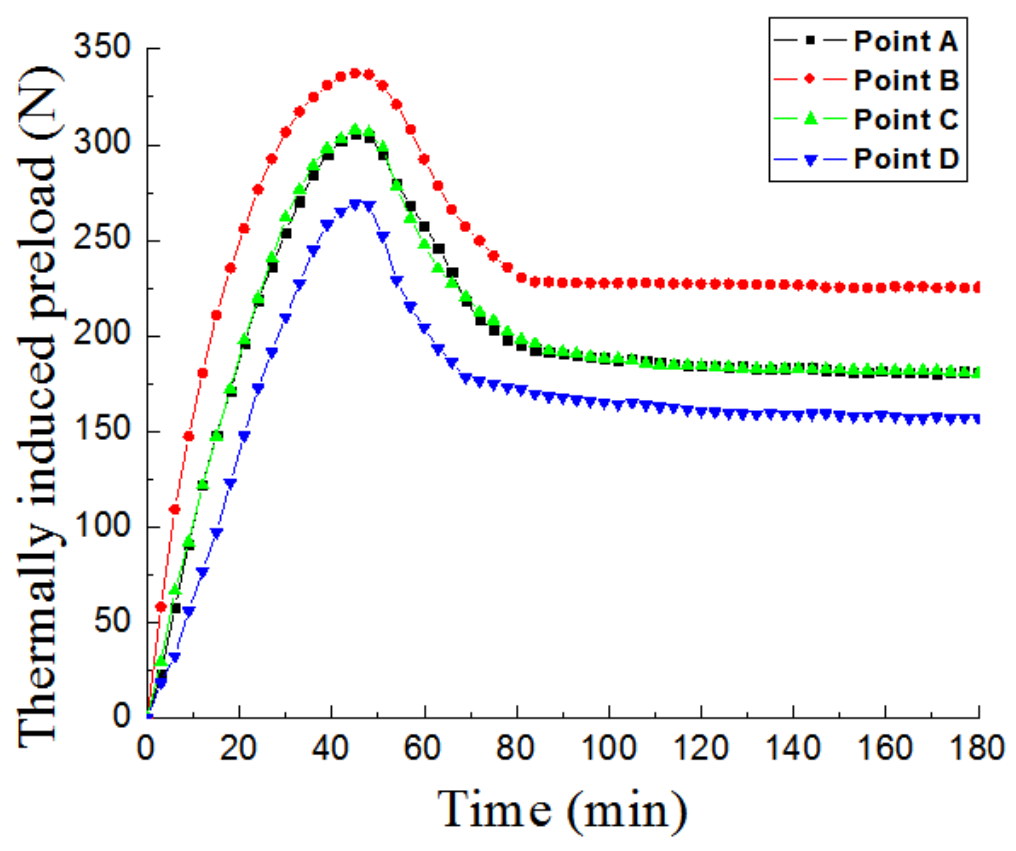

Fig. 12 Thermally-induced preload of bearings at different measuring points

The stiffness of the spindle bearing is closely related to the temperature rise. Fig. 13 shows the thermal stiffness of the bearings at different measuring points. From Fig.13, it can be seen that the stiffness of the B measuring point is the smallest, the $\mathrm{D}$ measuring point has the largest stiffness, and the stiffness of the $\mathrm{A}$ and $\mathrm{C}$ measuring points are not much different. This is Due to the effect of radial load, the spin friction torque between each rolling element and the ring of the bearing is unevenly distributed. The bearing temperature in the bearing zone is higher than that in the non-loading zone, resulting in uneven thermal expansion of the bearing rolling elements, inner and outer rings, so different measurements are made. Therefore, there are differences in bearing stiffness at different measuring points. This will cause thermal deformation of the spindle, resulting in a thermal error of the spindle unit, and reduce the machining accuracy of the machine tool. 


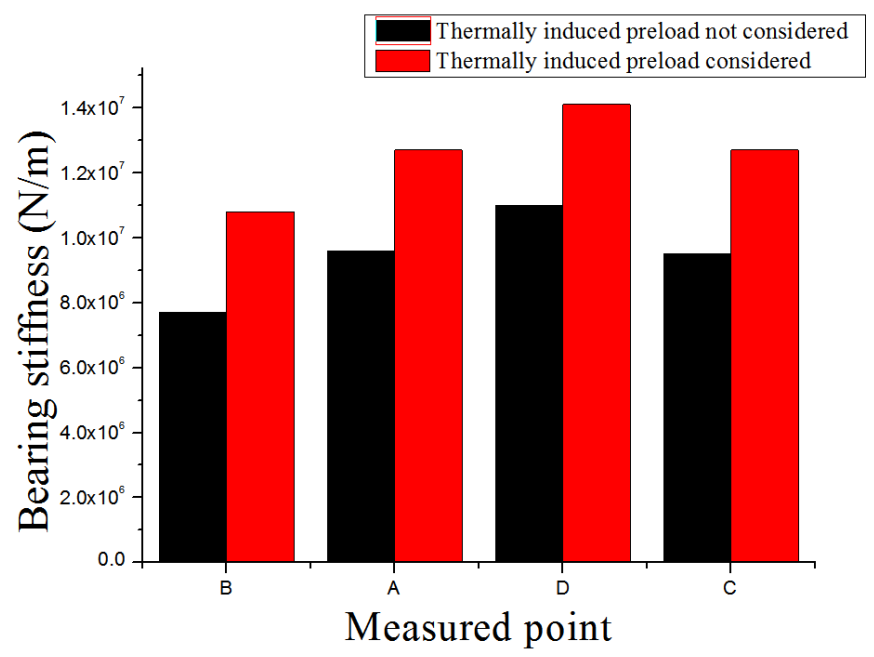

Fig. 13 Thermal stiffness of bearings at different measuring points

In addition, the spindle bearing temperature rise also has been compared with the ANSYS simulation results to prove the test based on FBG sensors accuracy. The specific results of the comparison are shown in Fig. 14. From Fig. 14, it can be seen that the maximum difference between the simulation and test results is $1.61{ }^{\circ} \mathrm{C}$, verifying the accuracy of the test results.

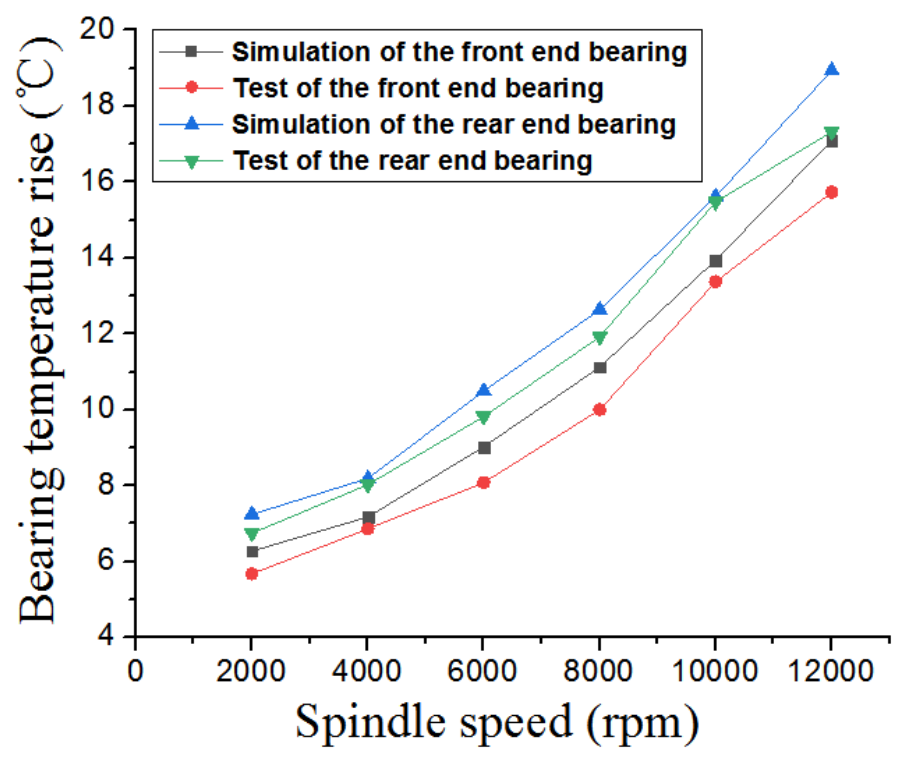

Fig. 14 The comparison of simulation and test results

\section{Conclusion}

Aiming at exploring the thermal stiffness characteristics of machine tool spindle bearings under the interaction of spindle speed, initial preload and cutting force, this paper builds a spindle unit thermal characteristics test system based on FBG sensors network, and processed the bearing thermal characteristics tests. Through the test and simulation results analysis, the following conclusions can be drawn: 
1) Considering that the FBG is sensitive to temperature and strain at the same time, a method of arranging two adjacent FBG sensors and pasting them perpendicular to each other is proposed to complete the temperature compensation.

2) The temperature rise and thermally induced preload of the spindle bearing both increase with the increase of the spindle speed. Especially when the spindle speed is higher than $10000 \mathrm{rpm}$, the temperature rise of the bearing and the thermally induced preload both appear to rise sharply first, then slowly drop, and finally reach a steady state.

3) There is an optimal initial preload under different spindle speeds to minimize the temperature rise of the spindle bearing and the thermally induced preload, and the higher the spindle speed, the greater the optimal initial preload.

4) The effect of cutting force divides the bearing into a load-bearing area and a nonload-bearing area. The thermal stiffness of the bearing in the load-bearing area is $30 \%$ lower than that in the non-load-bearing area, and the thermally induced preload also has an important influence on the thermal stiffness of the bearing.

\section{Acknowledgment}

The authors would like to acknowledge funding support from the National Key R\&D Program of China (No. 2018YFB2000504), National science foundation (No. 51805151) and Henan Provincial Department of Education Project (No. 19A460018), as well as the contributions from all collaborators within the projects mentioned.

\section{Declarations}

\section{Funding}

This research was funded by The National Key R\&D Program of China, grant number 2018YFB2000504, National science foundation, grant number 51805151, and Henan Provincial Department of Education Project,grant number 19A460018.

\section{Conflicts of interest/Competing interests}

No.

\section{Ethical Approval}

Not applicable.

\section{Consent to Participate}

Not applicable.

\section{Consent to Publish}

Not applicable.

\section{Availability of data and materials}

The data sets supporting the results of this article are included within the article.

Code availability (software application or custom code)

Not applicable.

\section{Authors Contributions}

methodology and writing — original draft preparation, DONG Yanfang and CHEN Feifan;; writing review and editing, LU 
Tuanliai; supervision, QIU Ming.

\section{Reference}

[1] Jin Chao, Wun Bo, Hu Youmin. Heat generation modeling of ball bearing based on internal load distribution [J]. Tribol Int, 2012, 45:8-15.

[2] Zhao CJ, Yu XK, Huang QX, Ge SD, Gao X. Analysis on the load characteristics and coefficient friction of angular contact ball bearing at high speed [J]. Tribol Int 2015, 87:5060 .

[3] Mingyao Liu, Weijian Zhou, Han Song, et al. Study of the temperature distribution of a machine tool spindle bearing based on FBG quasi-distributed sensing [J]. The International Journal of Advanced Manufacturing Technology, (2018) 98:263-274.

[4] Yanfei Zhang, Xiao hu Li, Jun Hong, Ke Yan, Sen Li. Uneven heat generation and thermal performance of spindle bearings [J]. Tribology International, 126 (2018): 324-335. [5] Wenwu Wu, Xiaohu Li, Feng Xu, et al. Investigating effects of non-uniform preload on the thermal characteristics of angular contact ball bearings through simulations $[\mathrm{J}]$. Proc IMechE Part J: J Engineering Tribology, 2014, 228(6) 667-681

[6] Wu Wenwu, Hong Jun, Li Yang, et al . Investigation of non-uniform preload effect on stiffness behavior of angular contact ball bearings [J]. Advances in Mechanical Engineering, 2017, 9(3): 1-19.

[7] Huang Weidi, Gan Chunbiao, Yang Shixi, et al . Analysis on the stiffness of angular contact ball bearings and its effect on the critical speed of a high speed motorized spindle [J]. Journal of Vibration and Shock, 2017, 36(10): 19-25.

[8] Jiandong Li, Yongsheng Zhu, Ke Yan, et al. An improved thermo-mechanical model for spindle transient preload analysis [J]. Proc IMechE Part J: J Engineering Tribology, 2019, $0(0): 1-14$.

[9] Ke Yan, Bei Yan, Yatai Wang, et al. Study on thermal induced preload of ball bearing with temperature compensation based on state observer approach [J]. International Journal of Advanced Manufacturing Technology, 2016: 1-12.

[10] Tianliang Li, Yuegang Tan, Zude Zhou. String-type based two-dimensional fiber Bragg grating vibration sensing principle and structure optimization [J]. Sensors and Actuators A: Physical, 259(2017): 85-95. 